\title{
The Effect of Rice Husk and Saw Dusk Filler on Mechanical Property of Bio Composite from Sago Starch
}

\author{
Rozanna Dewi ${ }^{1 *}$, Novi Sylvia ${ }^{1}$, M. Riza ${ }^{2}$ \\ ${ }^{I}$ Department of Chemical Engineering, Universitas Malikussaleh, Reuleut, Aceh, Indonesia. \\ ${ }^{2}$ Universitas Syiah Kuala, Aceh, Indonesia \\ *Corresponding authorE-mail: rozanna.dewi@ unimal.ac.id
}

Manuscript received 15 April 2021; revised 1 May 2021; accepted 15 June 2021. Date of publication 3 July 2021

\section{Abstract}

Some materials derived from plants can be used as a source of biodegradable thermoplastic materials such as rice, potatoes, corn, sweet potatoes, sago, etc. In this research, thermoplastic sago starch (TPS) with a mixture of two types of fillers was synthesized to become environmentally friendly composites that can be naturally degraded in a relatively short time compared to other conventional plastics which decompose in decades, hence can contribute to environmental conservation efforts. Increasing the strength of bio composite through the presence of fillers will expand its application such as for household application. Sago is available in large quantities in Indonesia and needs to be utilized optimally to increase its added value. TPS is synthesized using sorbitol as a plasticizer so that it becomes a starch paste. Composites are moulded by means of compression moulding using TPS and cellulose as a filler and Polypropylene (PP). The fillers used were sawdust and rice husk with several variations to obtain optimal combination, to improve the mechanical performance of the composites. For rice husk fibre, the highest tensile strength value $13.82 \mathrm{MPa}$, found at $40 \%$ fibre with ratio of TPS: PP 1: 0.5 , and the highest elongation value was $16.47 \%$ at $40 \%$ fibre at ratio of TPS : PP 1: 0.5 . For Sawdust fibre, the highest tensile strength value $11.08 \mathrm{MPa}$, obtained at $20 \%$ fibre at ratio of TPS : PP $1: 1$, and the highest elongation value was $18.57 \%$ at $20 \%$ fibre with ratio of TPS : PP $1: 1$. Type of filler has different effect on the tensile strength and elongation of the bio composite.

Keywords: Thermoplastic sago starch (TPS), cellulose, bio-composites, filler, mechanical properties.

\section{Introduction}

Most modern technologies require materials with a combination of extraordinary properties that cannot be achieved by common materials such as ferrous metals, ceramics and polymer materials. Composite is widely developed today because it is able to combine several properties of different characteristics into new properties and in accordance with the planned design. Composite consists of a main material (matrix) and a type of reinforcement which is added to increase the strength and stiffness of the matrix. This reinforcement is usually in the form of fiber. The fibers used can be natural fibers or synthetic fibers. Besides having structural capabilities, light and strong, environmentally friendly materials are also the demands of today's technology. One material that is expected to be able to fulfill this is composite material with natural fiber filling material. The advantages of natural fibers are low density, easy to obtain, cheaper prices, environmentally friendly, and not harmful to health.

Various problems on plastic waste and natural fiber waste have encouraged technology development to use environmentally friendly product nowadays. Plastic has been derived from several local starches such as cassava and sago. With certain modification, it has been proven to have similar characteristic with conventional plastic. To improve its characteristics, it can be reinforced with natural fiber such as straw, rice husks, wood husk, and cotton to become bio composite. Bio composites made from natural fiber has many advantages such as biodegradable, improved mechanical properties such as strength and stiffness. At the moment, the utilization of rice husk and sawdust are less efficient, and consider as waste from rice farming and furniture activity. Rice husk and sawdust can be used as a composite filler material; it is available in huge quantity, cheap and environmentally friendly. The mechanical and biodegradability properties of bio composite is studied to analyze the effect of natural fiber addition [1].

In this proposal, the plasticized thermoplastic starch wants to be modified with cellulose-based fillers, namely rice husks and sawdust with high temperature and pressure to become environmentally friendly composites. This environmentally friendly composite is expected to have better chemical, physical, mechanical, thermal and water absorption characteristics than thermoplastic starch alone. Eco-friendly composites are expected to be a solution to reduce plastic waste because they can decompose naturally in a relatively short time. The application of environmentally friendly composites is also very broad, which can be printed into household products, electronics, electricity, automotive, packaging, etc [2]. 


\section{Literature Review}

Thermoplastic is a plastic that can be softened repeatedly (recycled) by using heat. Thermoplastic is a polymer that becomes hard when cooled. Thermoplastic will melt at a certain temperature, adhere to changes in temperature and has the property of being reversible to its original nature such as hardening again when cooled. Thermoplastic starch is a thermoplastic product that uses starch as its raw material. The use of starch into thermoplastic starch is intended to obtain biodegradable properties that are not possessed by thermoplastic starch derived from conventional synthetic polymers. The biodegradable nature of a material indicates that the material can be decomposed by enzymes or the activity of certain organisms. In the biodegradation process, a material may undergo processes that involve oxidation, photo degradation, or hydrolysis [3].

Starch-based plastic mixtures have poor mechanical properties such as low tensile strength, stiffness, low elongation at break, low humidity stability and release small amounts of plasticizing molecules from starch matrix Modification of starch, use of compatibilizer, reinforcement, and improvement of process conditions, are expected to make starch as a conventional plastic substitution material.[4]. Films made from cellulose derivatives and a number of thermoplastic resins in the form of sheets and tubes can be used as wrappers, bags and covers [5]. Films from a mixture of starch and plasticizers can be used as packaging, but must meet certain mechanical properties [6].

\subsection{Thermoplastic Starch}

Several studies in the field of plastic using starch and polyurethane have been carried out. Ferrer et al., 2008 characterizes polyurethane networks derived from plant-based polyols comparing them to synthetic polyurethane networks. The results obtained are polyurethanebased plant polyols having lower tensile strength in accordance with the increase in polyurethane molecular weight [7] [8]. Transparent film mixture from PU based on castor oil and p-phenylene diamine soy protein (PDSP) was prepared by Liu et al 2008. Miscibility, morphology and properties of mixed films were tested by FTIR, DSC, DMA, SEM, adsorption moisture, thermal degradation and tensile tests. Both components are suitable for a large number of ratios as a result of strong hydrogen bonds or chemical cross-links that occur between PU and PDSP. Elongation, thermal stability, and water resistance of PU/PDSP films increase with the addition of PU [9] [10]. Lu et al., 2005 developed PU from rapeseed oil-based polyols, and then used it to modify glycerol plasticized starch (PS) to overcome the disadvantages of starch, namely poor mechanical properties and water sensitivity. The results showed that plasticized glycerol starch could be mixed with rapeseed oil-based PU at PU content below $20 \%$ and phase separation occurred when PU content increased. Addition of PU into the starch matrix also increases film resistance to water [11] [12].

Polyurethane pre polymer that are synthesized from isocyanates and polyols to strengthen starch thermoplastics. This research produced modified thermoplastic starch that was cross-linked with polyurethane pre polymer obtained from Diphenyl methane di isocyanate and castor oil polyol which had better mechanical, thermal and chemical characteristics than bioplastics and could biodegrade naturally. [13]. Subsequent research was carried out by adding chitosan as a reinforcement as well as antibacterial which can improve the mechanical performance of the resulting thermoplastic [13]. Chitosan has been shown to increase the strength of plastics and has water barrier properties when mixed with starch.

\subsection{Bio Composite}

Composite is a material formed from a combination of two or more materials that has different mechanical properties and characteristics from the constituent material. Composite consists of 2 main parts, namely the matrix that functions as an adhesive or binder and protects the filler from external damage and filler that serves as a reinforcement of the matrix. To form composite, it is required the presence of surface bonds between the matrix and filler. This bond between surfaces occurs because of the adhesion and cohesion forces. Composite material technology using natural fibers as reinforcement has been developed to replace synthetic fibers. Bio composites can be defined as composite materials consisting of natural polymers or bio fibers (natural fibers), which can be degraded as reinforcement. The use of natural fiber as a composite reinforcement has several advantages, including high specific strength and modulus, low density, low price, lower pollution emissions and can degraded naturally.

Several previous studies have been carried out to modify thermoplastic starch, namely winceyette fibre which are used to strengthen corn starch. The results obtained are an increase in the tensile properties of the thermoplastic and an increase in the ability to absorb water. In addition, the increase in thermal stability is also carried out by adding cellulose fibres such as newspapers, wood fibres, flax fibre and kapok fibre. In addition, microscale water hyacinth fibre dregs (Water Hyacinth Fibre/WHF) filled with tapioca biopolymer starch composites (Tapioca Starch Biopolymer / TSB) with WHF volume fraction in varying TSB matrices were carried out. SEM of the bio composite fracture surface for tensile samples displays good fibre distribution in the matrix and the interface bond between WHF and TSB. [14] [15]. Abaca composites without connector agent with $40 \%$ fibre had optimal properties when mechanical characterization was carried out and the results revealed that composites untreated with connector agents' increased tensile strength, flexibility and impact strength. [16]

Analyze of the effect of the volume fraction of the filler fibers of pineapple leaves on polyester resin matrix composites on tensile strength, showed the results that fibers which have a fiber orientation in the direction of the composite length so that when the composite given the force it will be able to withstand this force and be passed on by the fiber before the composite will break, but the relationship between variations in the volume of the short fiber particle fraction to the tensile strength of the composite shows that the tensile strength of the composite with short random fiber particles decreases with increasing volume of short random fiber fractions. This is due to the imperfect bond between fiber fillers and matrices along with the addition of fiber filler volume in the composite which causes many voids[17].

\section{Methods}

This research method included the stages of preparation of polymer fiber, producing starch thermoplastic and bio composite and stage of analysis. The analysis done was to measure mechanical property (tensile and elongation) of bio composite to understand its strength. 


\subsection{Preparation of Polymer Fiber}

Rice husk and sawdust was cut into small pieces and mashed using a blender. Furthermore, it sieved to homogeny into 50 mesh size. Furthermore, the sawdust and rice husks were dried using an oven at $103^{\circ} \mathrm{C}$ for 4 hours.

\subsection{Preparation of Thermoplastic Starch}

Rice husk and sawdust, sago powder and water are weighed according to the set up composition and mixed together. The variations of natural cellulose were $20 \%, 30 \%$ and $40 \%$. The mixture then heated and stirred until become gelatin at a temperature of $70^{\circ} \mathrm{C}$ for 25 minutes. MDI (Methylene Di-Isocyanate) and polyol was added with a predetermined ratio to modify the thermoplastic starch (TPS) by in-situ mechanism. Glycerol as plasticizer was added 10\% and stirred rigorously until homogeneous. The homogeneous mixture was dried using an oven at $80^{\circ} \mathrm{C}$ for 24 hours. The dried mixture will form like a crust and cut into smaller sizes.

\subsection{Preparation of Bio Composite}

Thermoplastic starch that has become crusted was blended into a finer size to facilitate mixing. Polypropylene (PP) was heated at $110^{\circ} \mathrm{C}$ until melted and mix with thermoplastic starch until homogeny. Thermoplastic starch ratio to Polypropylene were $1: 0.5,1: 1,1: 1.5$. The mixture was then printed in the glass casting to form a film and leave for 24 hours to dry it in an oven. When it dried the film was taken out and ready to be test specimen.

\subsection{Mechanical Testing}

The mechanical test is tensile test and elongation at break. Tensile strength test and elongation at break were performed by Electronic System Universal Testing Machines (ASTM D882-81)

\section{Results and Discussion}

Mechanical test was done using Tensile and elongation test. The tensile strength of a material is the tensile strength of the test material to accept the load without being damaged or broken. The value of tensile strength does not depend on the size of the material but because on the type of material. Other factors contribute to the strength such as the presence of impurities in the material, temperature and humidity of the test environment, and the preparation of specimens. Elongation is a change in maximum length before the bio composite is cut off. Elongation percentage presented the ability of bio composite to stretch to the maximum.

\subsection{Tensile Strength Test}

Mechanical testing of rice husk and sawdust bio composite was carried out using the Torsee's Electronic System test machine. The measurement results are carried out to determine the tensile strength and elongation. The relationship between rice husk filler and matrix (TPS) on bio composite tensile strength can be seen in Figure 1 below.

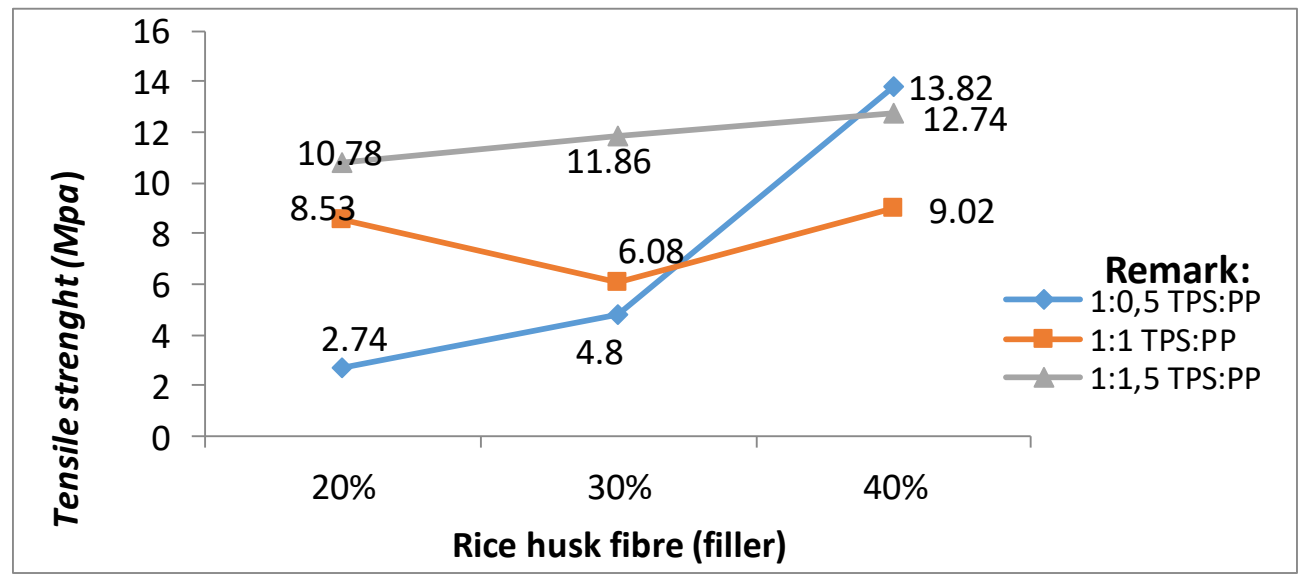

Fig 1. Tensile Strength of Bio Composite with Rice Husk Filler

The increase in tensile strength is influenced by the binding power between the filler with matrix and the addition of the volume of the rice husk fill fraction on the composite. The more filler used, tensile strength is increased. The addition of Polypropylene as well as has contributed to increasing of tensile strength where the higher tensile strength ware 13.82 Mpa of is observed at 40\% filler and 1:0.5 TPS : PP blending ratio. Polypropylene is used to improve composite strength and give plastic behaviour as the thermoplastic sago starch has limited strength if used as single matrix without additional synthetic polymer. However, addition polypropylene into the mixture will influence the biodegradability rate, hence it is required to look carefully at the amount of PP add into the mixture. Biodegradability of this composite will be discuss somewhere else. 
The increase in tensile strength is influenced by the binding strength between the fibre with a perfect matrix and the increase in the volume of the fibre fraction of the rice husk in the composite. Rice husk fibre contains silica (SiO2) which functions as a reinforcement in the material, the more rice husk fibre is given, and the value will increase. There was a decrease in tensile strength in the fibre bio composite 30\% with TPS: PP 1: 1 ratio of $6.08 \mathrm{MPa}$, due to areas that lacked fibre from uneven distribution of fibre, resulting in low internal stress in the area. Another factor that causes a decrease in the tensile strength of the bio composite was also due to the emergence of voids.

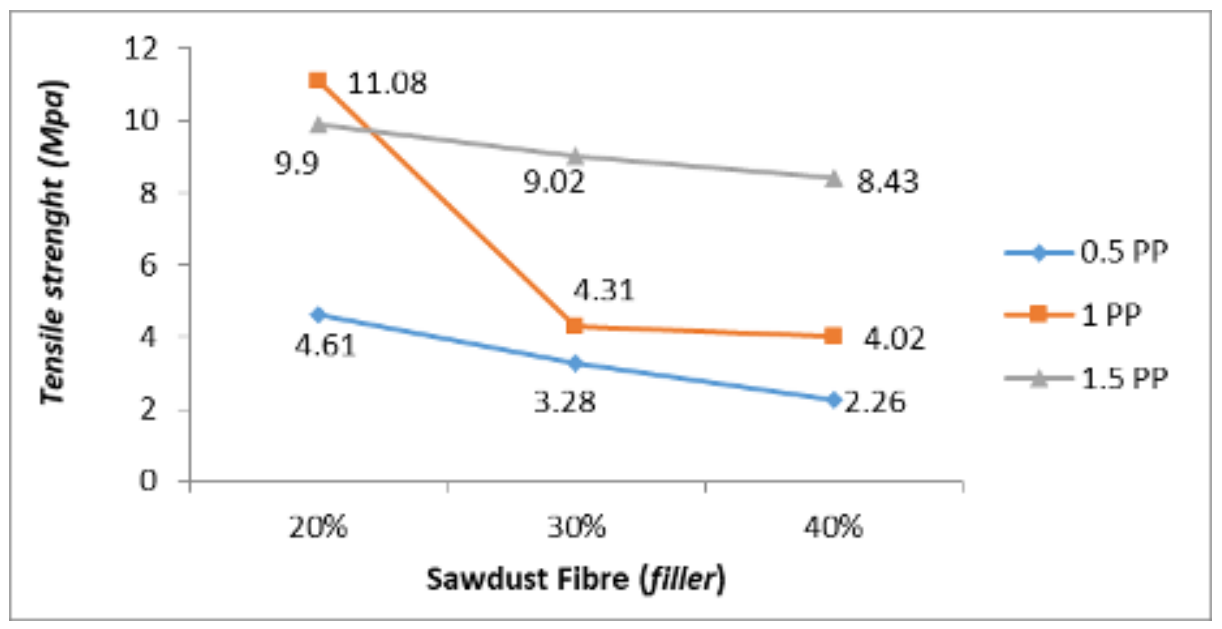

Fig 2. Tensile Strength of Bio Composite with Sawdust Filler

For sawdust filler, it can be seen from Figure. 2 that The highest tensile strength value was at the composition of $20 \%$ fibre and the ratio of TPS : PP 1: 1 with a value of $11.08 \mathrm{Mpa}$. As the amount of filler increases, the tensile strength of composite decreases. The behaviour shown was different with rice husk filler. The higher filler content will decrease the tensile strength. Type of filler has different effect on the tensile strength of the bio composite.

The decrease in tensile strength can also influence by sago matrix (TPS), because with the decreasing weight of the sago matrix (TPS), the matrix is not able to bind the filler well. As a result, when the load is applied, the load is not maximally distributed due to the weak bond between the filler and the matrix. Another factors that can affect a decrease in the strength of the composite was uneven mixture of the matrix and the filler used and the presence of voids (holes). In addition, it is also influenced by the position of the filler which is not related to each other which causes the bio composite to break easily in the matrix. For certain fibre, less filler used will reveal greater tensile strength, whereas too much filler used will not provide a balance with the weight of the matrix, then the tensile strength of the bio composite will be smaller.

\subsection{Percent Elongation Test}

Elongation percentage is the length increase of a test material due to the withdrawal load until just before experiencing fracture. The relationship of rice husk filler composition on elongation percentage can be seen in Figure. 3 below.

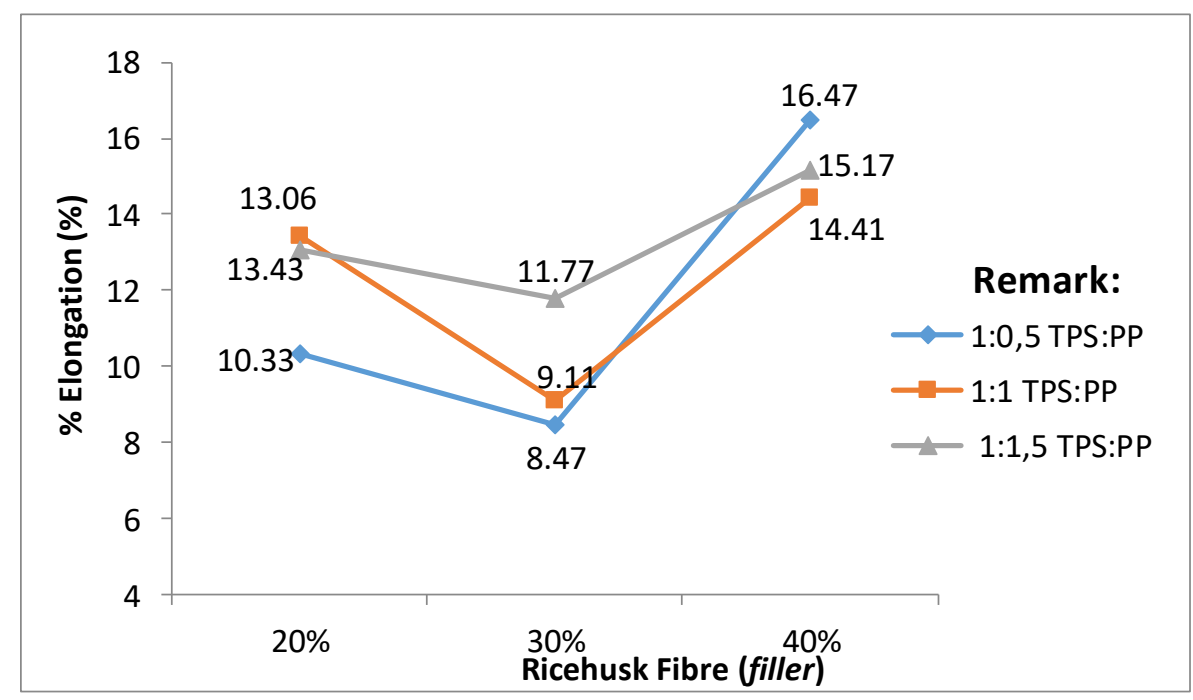

Fig 3. Percent Elongation of Bio Composite with Rice Husk Filler

Elongation is the percentage increase in the length of the composite material, which is measured from the initial length when it undergoes withdrawal to breaking. From Figure 3 it can be seen that the highest elongation value was shown by the $40 \%$ filler at $16.47 \%$ at ratio of TPS : PP $1: 0.5$ and the lowest elongation value was shown in the $30 \%$ filler at $8.47 \%$. More filler used will increase the percentage value of elongation, and vice versa. 


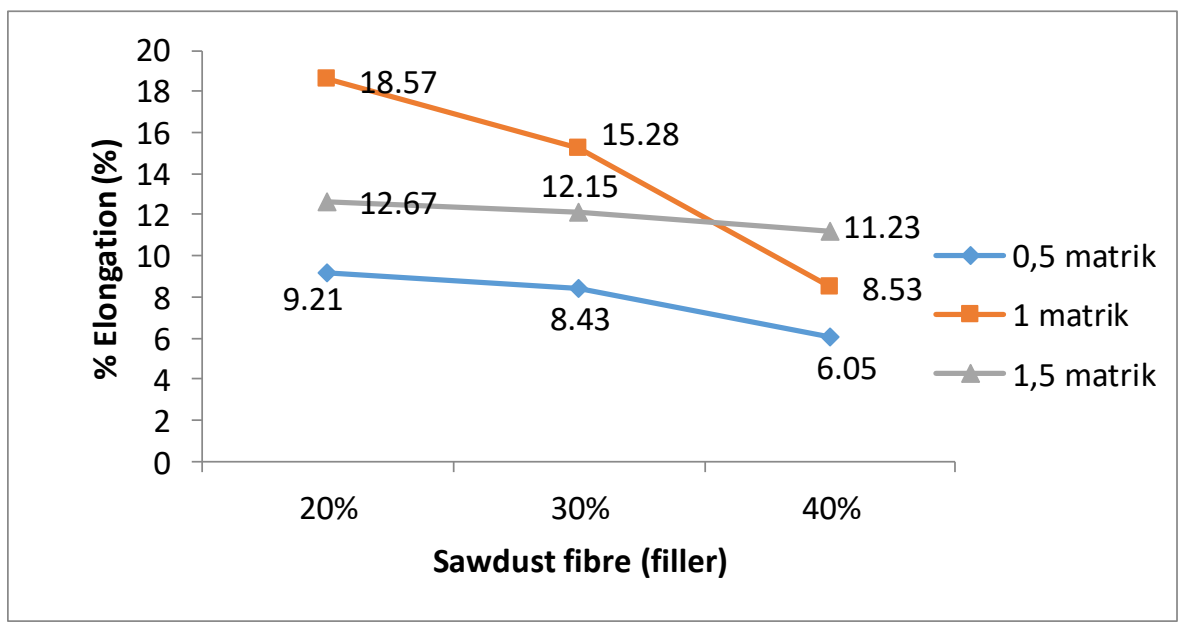

Fig 4. Percent Elongation of Bio Composite with Sawdust Filler

In Figure 4, the highest elongation test results are shown by the filler $20 \%$, which is $18.57 \%$ at the ratio of TPS : PP $1: 1$, and the lowest elongation value is shown in the $40 \%$ filler with elongation value of $6.05 \%$. In the $40 \%$ filler, the elongation decreased due to the increase in the weight fraction of the filler which was too much. This reduction in elongation is due to the increase in the number of fibre in the filler in the bio composite which will further prevent the polypropylene polymer from moving from one place to another so that it will result in early failure when it is loaded. Increasing amount of sawdust filler to the mixture will reduce the elongation value. The trend is different with the addition of rice rusk fibre, where adding more fibre will increase the elongation value.

\section{Conclusion}

For rice husk fibre, the highest tensile strength value was found $13.82 \mathrm{MPa}$ at $40 \%$ fibre with ratio of TPS: PP 1: 0.5, and the highest elongation value obtained was $16.47 \%$ at $40 \%$ fibre with ratio of TPS : PP 1: 0.5. For Sawdust fibre, the highest tensile strength value was obtained $11.08 \mathrm{MPa}$ at $20 \%$ fibre at the ratio of TPS : PP $1: 1$, while the highest elongation value obtained was $18.57 \%$ at $20 \%$ fibre with ratio of TPS : PP $1: 1$. Type of filler has different effect on the tensile strength and elongation of the bio composite. For rice husk, as the amount of filler increases, the tensile strength of composite was also increase, while the behaviour shown by sawdust fibre was the opposite. Increasing amount of sawdust filler to the mixture will reduce elongation percent, meanwhile addition of rice rusk fibre will increase the elongation percent.

\section{Acknowledgement}

This research was funded by internal fund from Universitas Malikussaleh on 2020. This research was done in 6 months period, with the assistance of two laboratory assistants at Chemical Engineering Laboratory, Engineering Faculty, Universitas Malikussaleh.

\section{References}

[1] S. Kumari and A. Harikrishnan, "Importance of Financial literacy For Sustainable Future Environment: A Research Among People In Rural Areas With Special Reference To Mandi District,Himachal Pradesh,” Int. J. Eng. Sci. Inf. Technol., vol. 1, no. 1, 2021, doi: 10.52088/ijesty.v1i1.36.

[2] M. Mahfut, M. V. Treesya Panjaitan, S. Wahyuningsih, T. Tripeni Handayani, and S. Sukimin, "Identification of Disease and Efforts to Protect Natural Orchid Plants Against Fungi Infection in the Liwa Botanical Garden," Int. J. Eng. Sci. Inf. Technol., vol. 1, no. 1, 2021, doi: 10.52088/ijesty.v1i1.39.

[3] C. E. Lane, I. Ahmad, I. Abdullah, and D. H. Mohd, "Effects of Rice husk modification with liquid natural rubber and exposure to electron beam radiation on the mechanical properties of NR/HDPE/Rice husk composites)," Sains Malaysiana, 2011.

[4] Z. QX, Y. ZZ, X. XL, N. K, and K. Y, "Preparation and Crystalline Morphology of biodegradable starch/clay nanocomposites," Polym. 48(24), pp. 7193-7200, 2007.

[5] W. Pudjiastuti, A. Listyarini, and Sudirman, "Polimer Nanokomposit Sebagai Master Batch Polimer," Ris. Ind., vol. VI, no. 1, pp. 51-60, 2012.

[6] S. Romadhona, F. Kurniawan, and J. Tistogondo, "Project Scheduling Analysis Using the Precedence Diagram Method (PDM) Case Study: Surabaya's City Outer East Ring Road Construction Project (Segment 1),” Int. J. Eng. Sci. Inf. Technol., vol. 1, no. 2, 2021, doi: 10.52088/ijesty.v1i2.56.

[7] X. K. and S. S. N. Ferrer M, "Physical properties of polyurethane plastic sheets produced from Poliol from Canola oil," Biomacro, pp. 2203-220, 8, 2007.

[8] R. Rinaldy and M. Ikhsan, "Determinant Analysis Of Conflict On Project Results In Aceh Province," Int. J. Eng. Sci. Inf. Technol., vol. 1, no. 1, 2021, doi: 10.52088/ijesty.v1i1.37.

[9] L. Dagang, T. Huafeng, Z. Lina, and C. P. R, "Structure and properties of blendfilms prepared from castor oli-based polyurethane/soy protein derivative," J. Mater. Andin. Ind. Eng. Chem. Res., pp. 9330-9336, 2008.

[10] D. Kumar, "Power System Restoration Using Multilayer Perceptron," Int. J. Eng. Sci. Inf. Technol., vol. 1, no. 1, 2021, 
doi: 10.52088/ijesty.v1i1.35.

[11] L. Yoshang, T. Lan, B. Francoise, and S. Rondot, "Innovative plasticized starch films modified waterborne polyurethane from renewable resources," Carbohydr. Polym., pp. 61, 174 - 182, 2005.

[12] M. F. Firmansyah and H. Z. Maulana, "Empirical Study of E-Learning on Financial Literacy and Lifestyle : A Millenial Urban Generations Cased Study," Int. J. Eng. Sci. Inf. Technol., vol. 1, no. 3, pp. 75-81, 2021.

[13] R. Dewi, H. Agusnar, B. Wirjosentono, and M. Riza, "Synthesis of modified thermoplastic starch (TPS) using in-situ technique," Adv. Environ. Biol., vol. 8, no. 18, pp. 26-33, 2014.

[14] H. Abral et al., "Characterization of Tapioca Starch Biopolymer Composites Reinforced with Micro Scale Water Hyacinth Fibers," Starch, WILEY-VCH Verlag GmbH Co. KGaA, Weinheim, 2018.

[15] J. S Pasaribu, "Development of a Web Based Inventory Information System," Int. J. Eng. Sci. Inf. Technol., vol. 1, no. 2, 2021, doi: 10.52088/ijesty.v1i2.51.

[16] R. Punyamurthy, D. lakshmi S. Kumar, R. P. G, Ranganagowda, B. Bennehalli, and C. V. Srinivasa, "Mechanical properties of abaca fiber reinforced polypropylene composites: Effect of chemical treatment by benzenediazonium chloride," J. King Saud Univ. - Eng. Sci., 2015.

[17] Paryanto, "Potensi Pemanfaatan Limbah Kayu sebagai Bahan Baku Papan Partikel," Tersedia http//www.cybertokoh.com. 15 Januari 2012. 